\title{
Perencanaan Peningkatan Jalan Pecangaan-Damaran Kabupaten Jepara
}

\author{
Suci Ariani Khumairo' 1), Yasin Musthofa' ${ }^{2)}$, Ibnu Toto Husodo ${ }^{3)}$, Slamet Budirahardjo ${ }^{4}$ \\ 1) 2) 3) Program Studi Teknik Sipil, Fakultas Teknik Dan Informatika, Universitas PGRI Semarang \\ Email : succi.any@gmail.com ${ }^{1)}$, musthofayasin7@gmail.com ${ }^{2)}$, sipilupgris@gmail.com ${ }^{3)}$
}

\begin{abstract}
Abstrak
Peningkatan volume lalu lintas yang tidak diimbangi dengan kapasitas jalan yang memadai menyebabkan meningkatnya kepadatan volume jalan. Oleh karena itu diperlukan adanya perencanaan peningkatan jalan yang memadai terhadap kondisi volume lalulintas saat ini. Tujuan penelitian ini adalah untuk menghitung tebal perkerasan jalan menggunakan metode Bina Marga 2002 serta total anggaran biaya yang diperlukan pada Jalan Pecangan-Damaran Jepara. Pada perencanaan peningkatan Jalan Pecangaan-Damaran Kabupaten Jepara menggunakan perkerasan lentur (flexible pavement) metode Bina Marga 2002 dengan umur rencana 10 tahun. Berdasarkan hasil analisa dan perhitungan perencanaan peningkatan Jalan Pecangaan-Damaran Kabupaten Jepara dapat diperoleh nilai DS (Degree Of Saturation) eksisting sebesar 0,91 maka untuk itu dilakukan peningkatan jalan dengan pelebaran dari $6 \mathrm{~m}$ menjadi $11 \mathrm{~m}$ dengan susunan konstruksi perkerasan untuk tebal lapis permukaan setebal $10 \mathrm{~cm}$ dengan campuran ATB setebal $5 \mathrm{~cm}$ dan AC-WC setebal $5 \mathrm{~cm}$, lapis pondasi atas setebal $15 \mathrm{~cm}$ menggunakan agregat kelas A (CBR 100\%), serta lapis pondasi bawah setebal $39 \mathrm{~cm}$ menggunakan agregat kelas C (CBR 60\%). Rencana anggaran biaya perencanaan peningkatan Jalan Pecangaan-Damaran Kabupaten Jepara sebesar Rp.7.233.141.147,57.
\end{abstract}

Kata kunci : peningkatan perencanaan jalan, bina marga, tebal lapis perkerasan

\begin{abstract}
Increased traffic volume which is not balanced with adequate road capacity leads to increased road volume density. Therefore it is necessary to have an adequate road improvement plan to the current traffic volume conditions. The purpose of this plan is to calculate the thickness of road pavement using the Bina Marga 2002 method and the total budget needed. In planning for the improvement of Pecangaan - Damaran Road, Jepara Regency uses the flexible pavement method of the Bina Marga 2002 with a 10-year plan life. Based on the results of analysis and calculation of planning for the improvement of Pecangaan - Damaran Road in Jepara Regency, the existing DS (Degree Of Saturation) value can be obtained by 0.91 so that the road is increased by widening

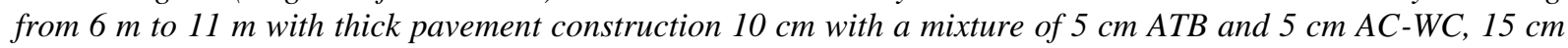
thick foundation layer using class A aggregate (CBR 100\%), and $39 \mathrm{~cm}$ thick foundation layer using class $C$ aggregate (CBR 60\%). The planned cost budget plan for the increase of Pecangaan - Damaran Road in Jepara Regency is Rp.7.233.141.147,57.
\end{abstract}

Keywords: increase in road planning, bina marga, thick pavement.

\section{PENDAHULUAN}

Jalan raya merupakan salah satu transportasi darat yang keberadaannya sangat diperlukan untuk menunjang kelancaran transportasi dan perekonomian yang baik. Tersedianya jalan raya yang baik akan memberikan pelayanan terhadap kendaraan guna meningkatkan kemudahan akses bagi suatu wilayah.

Dengan berjalannya waktu maka bertambahnya kepemilikan kendaraan, serta kemajuan di bidang industri dan perdagangan, serta bertambahnya distribusi barang dan jasa menyebabkan peningkatan volume lalu lintas namun tidak diikuti dengan sarana dan prasarana jalan yang memadai. Dengan meningkatnya perkembangan sektor perekonomian dan industri, makan akan bertambahnya kebutuhan sarana dan prasarana transportasi jalan yang baik, aman, dan mempunyai manfaat untuk masa mendatang.

Berdasarkan UU RI Nomor 38 Tahun 2004 jalan adalah prasarana transportasi darat yang meliputi segala bagian jalan, termasuk bangunan pelengkap dan perlengkapannya yang diperuntukkan bagi lalu lintas, yang berada pada permukaan tanah, di atas permukaan tanah, di bawah permukaan tanah dan/atau air, serta di atas permukaan air, kecuali jalan kereta api, jalan lori, dan jalan kabel. 
Penelitian ini dilakukan bertujuan untuk merencanakan peningkatan jalan PecangaanDamaran Kabupaten Jepara yang meliputi analisa volume kapasitas jalan saat ini, analisa rancangan tebal perkerasan jalan dengan menggunakan flexible pavement, dan menghitng besarnya anggaran biaya yang diperlukan pada perencanaan peningkatan jalan.

\section{METODE}

Dalam perencanaan ini menggunakan rumus bina marga 2002 :

$$
\begin{array}{r}
\log _{10}\left(\mathrm{~W}_{18}\right)=\mathrm{Z}_{\mathrm{R}} \times \mathrm{So}+9,36 \times \log _{10}(\mathrm{ITP}+1) \\
-0,20+\frac{\log 10\left[\frac{\Delta I P}{I P O-I P f}\right]}{0,40+\frac{1094}{(I T P+1)^{5,19}}}+ \\
2,32 \times \log _{10}\left(\mathrm{M}_{\mathrm{R}}\right)-8,07 \text { (1) }
\end{array}
$$

Keterangan :

$\mathrm{W}_{18}=$ Perkiraan komulatif beban sumbu standar ekivalen

$\mathrm{Z}_{\mathrm{R}}=$ Deviasi normal standar

So $=$ Gabungan kesalahan standar dari prediksi lalu lintas dan prediksi kerja

ITP = Indeks Tebal Perkerasan

$\Delta \mathrm{IP}=$ Perbedaan indeks permukaan awal dan akhir

$\mathrm{M}_{\mathrm{R}} \quad=$ Modulus resilient

\section{Tanah Dasar}

Kekuatan dan keawetan perkerasan jalan tergantung pada sifat - sifat dan daya dukung tanah dasar. Modulus Resilien $\left(\mathrm{M}_{\mathrm{R}}\right)$ sebagai parameter tanah dasar yang digunakan dalam perencanaan. Modulus resilien $\left(\mathrm{M}_{\mathrm{R}}\right)$ tanah dasar dapat diperkirakan dari CBR standar dan hasil atau nilai tes soil index. Korelasi modulus resilien dengan nilai CBR (Heukelom \& Klomp) berikut ini dapat digunakan untuk tanah berbutir halus (fine-grained soil) dengan nilai CBR terendam 10 atau lebih kecil.

$\mathrm{M}_{\mathrm{R}}(\mathrm{psi})=1500 \times \mathrm{CBR}$

\section{Angka ekivalen beban gandar sumbu kendaraan}

a) Untuk sumbu tunggal roda tunggal kendaraan (STRT)

$$
\left[\frac{\text { beban sumbu (ton) }}{5,4}\right]^{4}
$$

b) Untuk sumbu tunggal roda ganda kendaraan (STRG)

$$
\left[\frac{\text { beban sumbu (ton) }}{8,16}\right]^{4}
$$

c) Untuk sumbu ganda roda ganda kendaraan (SGRG)

$$
0,086 x\left[\frac{\text { beban sumbu (ton) }}{8,16}\right]^{4}
$$

d) Untuk sumbu triple roda ganda kendaraan (STrRG)

$$
0,054 x\left[\frac{\text { beban sumbu (ton) }}{8,16}\right]^{4}
$$

\section{Reabilitas}

Lalu Lintas Pada Lajur Rencana $\left(\mathrm{W}_{18}\right)$

$$
\mathrm{W}_{18}=\mathrm{D}_{\mathrm{D}} \times \mathrm{D}_{\mathrm{L}} \times \widehat{w}_{18}
$$

Dimana :

$D_{D}=$ faktor distribusi arah.

$\mathrm{D}_{\mathrm{L}}=$ faktor distribusi lajur.

$\widehat{w}_{18}=$ beban gandar standar komulatif untuk dua arah.

\section{Koefisien drainase}

Faktor untuk memodifikasi koefisien kekuatan relatif ini adalah koefisien drainase $(\mathrm{m})$ dan disertakan kedalam persamaan Indeks Tebal Perkerasan (ITP) bersama-sama dengan koefisien kekuatan relatif (a) dan ketebalan (D).

\section{Indeks Permukaan (IP)}

Adapun beberapa ini IP beserta artinya adalah seperti yang tersebut di bawah ini :

IP $=2,5$ : menyatakan permukaan jalan masih cukup stabil dan baik.

IP $=2,0:$ menyatakan tingkat pelayanan terendah bagi jalan yang masih mantap.

IP $=1,5:$ menyatakan tingkat pelayanan terendah yang masih mungkin (jalan tidak terputus).

IP $=1,0:$ menyatakan permukaan jalan dalam keadaan rusak berat sehingga sangat mengganggu lalu lintas kendaraan

\section{Koefisien Kekuatan Relatif (a)}

Berdasarkan jenis dan fungsi material lapis perkerasan, estimasi Koefisien Kekuatan Relatif dikelompokkan ke dalam 5 kategori, yaitu : beton aspal (asphalt concrete), lapis pondasi granular (granular base), lapis pondasi bawah granular (granular subbase), cementtreated base (CTB), dan asphalt-treated base (ATB). 
Tahapan penelitian secara lengkap seperti tampak pada diagram alir penelitian seperti tampak pada Gambar 1.

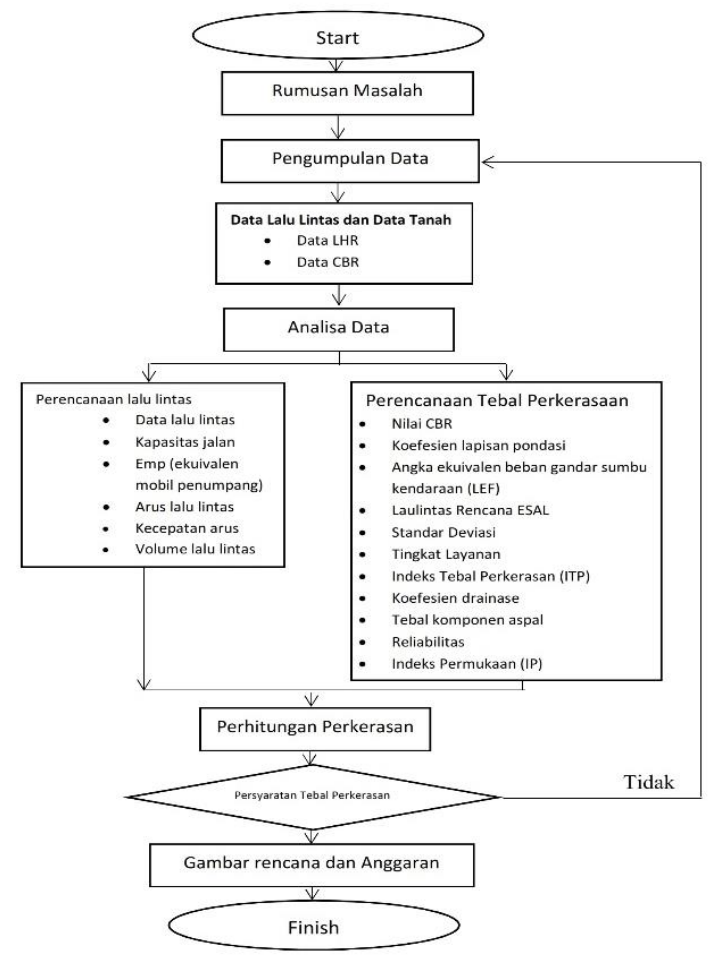

Gambar 1. Diagram alir penelitian

\section{HASIL DAN PEMBAHASAN}

Berdasarkan Dari data sekunder yang didapat dari Dinas Perhubungan Kabupaten Jepara pada tahun 2017, dalam perhitungan dan analisa diketahui dari total semua kendaraan yang melintasi jalan Pecangaan - Damaran Jepara dalam 1 tahun (2017) sebesar : 57147 smp/jam seperti dalam tabel 1 .

Tabel 1. LHR jalan Pecangaan-Damaran Jepara

\begin{tabular}{cc}
\hline Jenis kendaraan & $\begin{array}{c}\text { Lintas Harian Rata- } \\
\text { rata }\end{array}$ \\
\hline Kendaraan Ringan & 42670 \\
Mobil Penumpang & 10861 \\
3 & 404 \\
5A & 219 \\
5B & 173 \\
6B & 1428 \\
7A & 991 \\
8 & 401 \\
\hline
\end{tabular}

Sumber : Dinas Perhubungan Kabupaten Jepara tahun 2017
Adapun perhitungan LHRT pada volume jam puncak dapat dilihat pada tabel 2.

Menurut Bina Marga 2002, angka ekivalen tiap beban gandar (E) dirumuskan sebagai berikut :

a. Mobil penumpang gol 2,3,4 =0,0012+ $0,0012=0,0024$

b. Bus sedang gol $5 \mathrm{~A}=0,0098+0,027=$ 0,0368

c. Bus besar gol $5 \mathrm{~B}=0,064+0,175=0,239$

d. Truk sedang gol $6 \mathrm{~B}=0,796+2,17=2,966$

e. Truk besar gol $7 \mathrm{~A}=1,79+2,4=4,19$

Tabel 2. LHRT jalan Pecangaan-Damaran Jepara

\begin{tabular}{clccc}
\hline No & $\begin{array}{c}\text { Jenis } \\
\text { Kendaraan }\end{array}$ & $\begin{array}{c}\text { Jumlah } \\
\text { Kendaraan }\end{array}$ & $\begin{array}{c}\text { Faktor } \\
(\mathbf{k})\end{array}$ & LHRT \\
\hline 1 & $\begin{array}{l}\text { Sepeda } \\
\text { motor }\end{array}$ & 5411 & 0,09 & 60122 \\
2 & Mobil & 958 & 0,14 & 6842 \\
& penumpang & & & \\
3 & Bus sedang & 99 & 0,14 & 707 \\
4 & Bus besar & 87 & 0,14 & 621 \\
5 & Truk sedang & 155 & 0,14 & 1107 \\
6 & Truk besar & 94 & 0,14 & 671 \\
\hline & Jumlah & 6804 & & 70071 \\
\hline
\end{tabular}

Sumber : Dinas Perhubungan Kabupaten Jepara Tahun 2017

Lalu lintas pada lajur rencana $\left(\mathrm{W}_{18}\right)$ diberikan dalam komulatif beban gandar standar. Untuk mendapatkan perhitungan lalu lintas lajur rencana rumus sebagai berikut :

$$
\widehat{W} 18=\operatorname{LHR} x E
$$

a. $\widehat{W} 18$ mobil penumpang $=6843 \times 0,0024=16,42$

b. $\widehat{W} 18$ bus sedang $=707 \times 0,0368=26,02$

c. $\widehat{W} 18$ bus besar $=621 \times 0,239=148,42$

d. $\widehat{W} 18$ truk sedang $=1107 \times 2,966=3283,36$

e. $\widehat{W} 18$ truk besar $=671 \times 4,19=2811,49$ Total $=6286$

$\mathrm{W}_{18}$ perhari $=\mathrm{D}_{\mathrm{D}} \times \mathrm{D}_{\mathrm{L}} \times \widehat{W} 18$

$$
\begin{aligned}
& =0,5 \times 90 \times 6286 \\
& =282870
\end{aligned}
$$

$\mathrm{W}_{18}$ pertahun $=365 \times \mathrm{W}_{18}$ perhari

$$
=365 \times 282870
$$$$
=103247550
$$

$\mathrm{W}_{18}$ selama UR $=\mathrm{W}_{18}$ pertahun $\mathrm{x} \frac{(1+i)^{n}-1}{i}$

$$
\begin{aligned}
& =103247550 \mathrm{x} \frac{(1+7,1 \%)^{10}-1}{7,1 \%} \\
& =1433270072
\end{aligned}
$$


Dari perhitungan dan nilai grafik pada Gambar 2 dapat diketahui nilai CBR sebesar 1,65\%. Maka dapat diketahui nilai Modulus Resilien tanah (MR tanah).

$$
\begin{aligned}
\mathrm{M}_{\mathrm{R}} \text { Tanah } & =1500 \times(\mathrm{CBR}) \\
& =1500 \times 1,65 \\
& =2475 \mathrm{psi}
\end{aligned}
$$

Rekomendasi tingkat Reabilitas untuk jalan kolektor adalah 80 - 95 dan untuk deviasi standar (So) adalah 0,40 - 0,50.

Indeks permukaan pada umur rencana (IP0) adalah $3,9-3,5$.

Jalan yang direncanakan adalah jalan kolektor maka didapat nilai $\mathrm{IPt}=2,0$

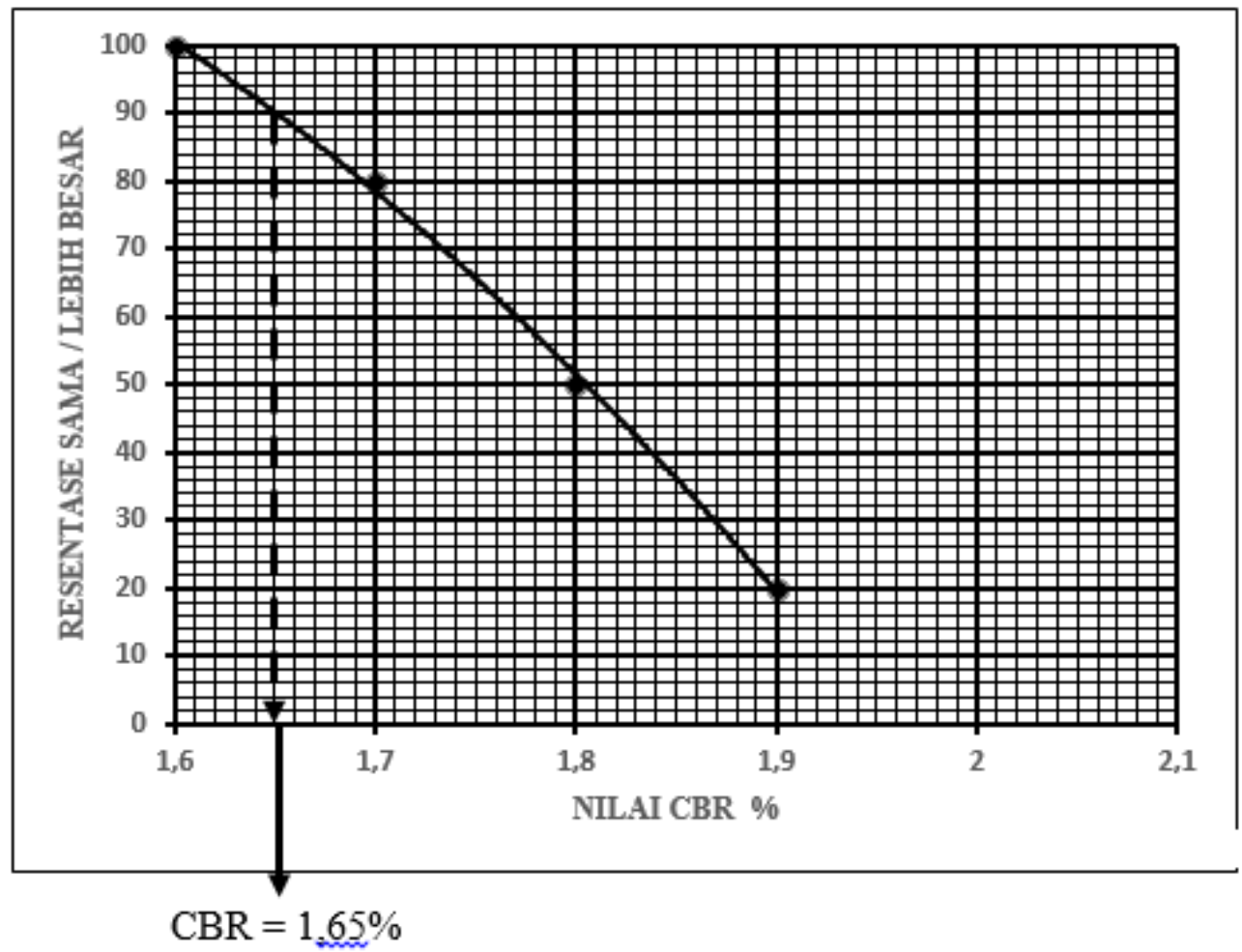

Gambar 2. Perhitungan dan nilai grafik CBR

\section{Desain Tebal Lapis Perkerasan}

Tebal lapis perkerasan dapat dihitung dengan menentukan nilai koefisien kekuatan relatif (a), koefisien drainase (m) dan Indeks Tebal Perkerasan (ITP) dari hasil analisa dan perhitungan didapat nilai

$$
\begin{aligned}
\text { a1 } & =0,40 \\
\text { a2 } & =0,24 \\
\text { a3 } & =0,26 \\
\mathrm{~m} 2 & =1,00 \\
\mathrm{~m} 3 & =1,00 \\
\mathrm{ITP} 1 & =3,97 \mathrm{~cm} \\
\mathrm{ITP} 2 & =5,34 \mathrm{~cm} \\
\mathrm{ITP} 3 & =10,31 \mathrm{~cm} \\
\text { D1 } & =\frac{\text { ITP1 }}{a 1}=\frac{3,97}{0,40}=9,9 \mathrm{~cm} \rightarrow 10 \mathrm{~cm}
\end{aligned}
$$

Batas minimum tebal perkerasan lapis permukaan adalah $10 \mathrm{~cm}$

$$
\mathrm{D}_{2}=\frac{I T P 2-I T P 1}{a 2 . m 2}=\frac{5,34-3,97}{0,24 \times 1,0}=5,7 \mathrm{~cm} \rightarrow 6 \mathrm{~cm}
$$

Batas minimum tebal perkerasan lapis pondasi atas adalah $15 \mathrm{~cm}$. Dari perhitungan tersebut didapat $6 \mathrm{~cm}$ maka tebal perkerasan lapis pondasi atas menggunakan $15 \mathrm{~cm}$.

$$
\begin{aligned}
\mathrm{D}_{3} & =\frac{I T P 3-(a 1 \cdot D 1+a 2 \cdot m 2 \cdot d 2)}{a 3 \cdot m 3} \\
& =\frac{10,31-(0,40 \times 10+0,24 \times 1 \times 15)}{0,26 \times 1,0} \\
& =38,12 \mathrm{~cm} \rightarrow 39 \mathrm{~cm}
\end{aligned}
$$

Rekapitulasi hasil analisa tebal perkerasan seperti pada Gambar 3 


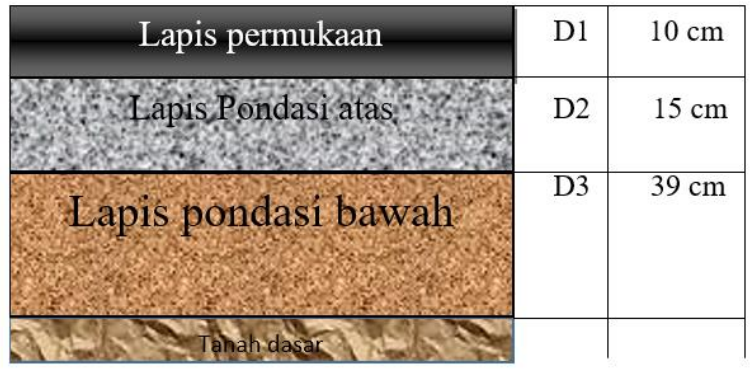

Gambar 3. Tebal lapis perkerasan

\section{Rencana Anggaran Biaya}

Setelah mengetahui tebal masing-masing lapis perkerasan maka selanjutnya dapat diperhitungkan Rencana Anggaran Biaya (RAB) untuk lapis perkerasan yang sudah dihitung. Hasil lengkap analisa RAB seperti tampak pada Tabel 3.

Tabel 3. Rencana Anggaran Biaya (RAB)

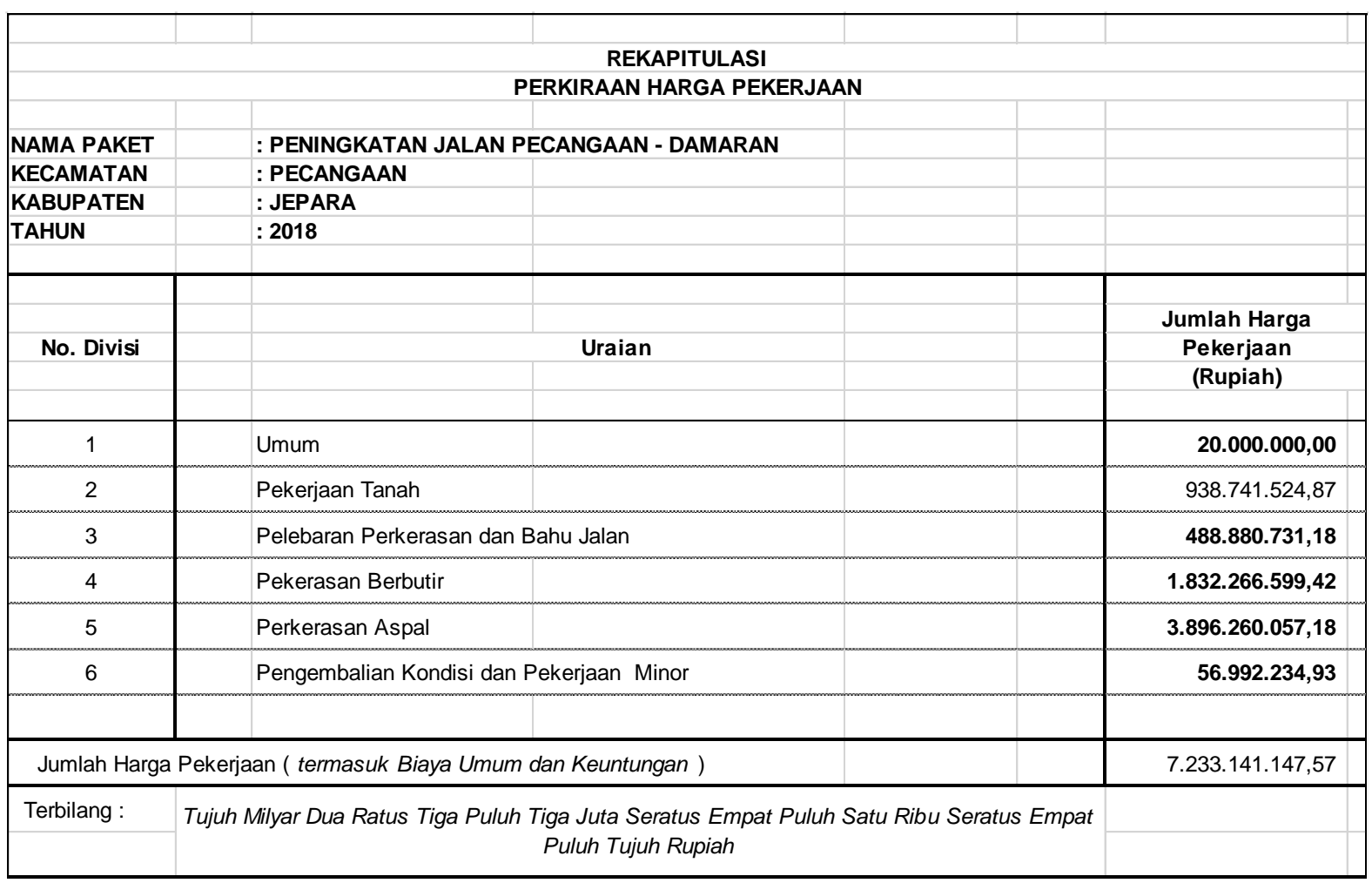

\section{KESIMPULAN}

Beberapa kesimpulan yang diperoleh dari pembahasan antara lain:

a. Dari hasil perhitungan dengan berpedoman Manual Kapasitas Jalan Indonesia (MKJI 1997), yang semula dapat diketahui derajat kejenuhan (DS) 1,228 melebihi batas maksimal derajat kejenuhan 1 maka kondisi jalan tersebut perlu adanya peningkatan kapasitas jalan atau pelebaran jalan masingmasing 2,5 meter.

b. Menghitung Derajat Kejenuhan (DS)

Untuk menghitung derajat kejenuhan perencanaan ini dihitung pada pagi hari dan sore hari. Adapun perhitungan yang digunakan menggunakan acuan rumus dari Manual Kapasitas Jalan Indonesia (MKJI 1997) dan data lalu lintas diperoleh dari Dinas Perhubungan Jepara yaitu :

$\mathrm{DS}=\mathrm{Q} / \mathrm{C}$

Diketahui : Q pagi $=3289 \mathrm{smp} / \mathrm{jam}$

$$
\begin{aligned}
\mathrm{Q} \text { sore } & =2835 \mathrm{smp} / \mathrm{jam} \\
\mathrm{C} & =3341,96 \mathrm{smp} / \mathrm{jam}
\end{aligned}
$$

Penyelesaian:

$$
\begin{aligned}
\text { DS pagi }=\mathrm{Q} / \mathrm{C} \\
\\
=3289 / 3341,96 \\
=0,98
\end{aligned}
$$$$
\text { DS sore } \quad=\mathrm{Q} / \mathrm{C}
$$$$
=2835 / 3341,96
$$$$
=0,84
$$ 
Jadi, Nilai DS (Degree of Saturation) adalah 0,91

Dalam perencanaan ini dengan pelebaran 2,5 $\mathrm{m}$ dapat mengurangi tingkat kejenuhan pada ruas Jalan Pecangaan - Damaran Kabupaten Jepara.

c. Menghitung Kecepatan Arus Bebas Lalu Lintas

Persamaan untuk menghitung kecepatan arus bebas mengacu pada MKJI tahun 1997 yaitu :

$$
\begin{array}{r}
\mathrm{FV}=\left(\mathrm{FV}_{0}+\mathrm{FV}_{\mathrm{W}}\right) \times \mathrm{FFV}_{\mathrm{SF}} \times \mathrm{FFV}_{\mathrm{RC}} \\
=(42+7) \times 0,86 \times 1,00 \\
=42,14 \mathrm{~km} / \mathrm{jam}
\end{array}
$$

Jadi, Kecepatan arus bebas yang semula $33,54 \mathrm{~km} / \mathrm{jam}$ setelah dilakukan perhitungan perencanaan pelebaran 2,5 meter kecepatan arus bebas menjadi $42,14 \mathrm{~km} / \mathrm{jam}$.

d. Hasil analisis perhitungan pelebaran perkerasan jalan dengan menggunakan aspal dengan spesifikasi sebagai berikut :

a) Lapis permukaan setebal $10 \mathrm{~cm}$ dengan campuran ATB setebal $5 \mathrm{~cm}$ dan AC $5 \mathrm{~cm}$.

b) Lapis Pondasi Atas setebal $15 \mathrm{~cm}$ dengan menggunakan material agregat kelas $\mathrm{A}$.

c) Lapis Pondasi Bawah setebal $39 \mathrm{~cm}$ dengan menggunakan material agregat kelas $\mathrm{C}$.

e. Rekapitulasi kuantitas dan harga untuk pelebaran Jalan Pecangaan-Damaran Kabupaten Jepara Rp 7.233.141.147,57

Dari perencanaan yang kami buat, saran yang dapat berikan adalah sebagai berikut :

a. Perlu adanya perencanaan yang matang pada pelebaran Jalan Pecangaan -Damaran Kabupaten Jepara agar tercapai kualiatas jalan yang bagus.

b. Perlu adanya peningkatan mutu pada persiapan dan perkerasan badan Jalan Pecangaan - Damaran Kabupaten Jepara agar tercapai pembangunan jalan yang memberikan rasa nyaman dan aman pada pengguna jalan.

\section{DAFTAR PUSTAKA}

AASHTO. 1993. Guide For Design Of Pavement Structures. Washington DC : AASHTO
Dinas Perhubungan. 2017. Data Lalu Lintas Harian Rata- Rata. Jepara.

Direktorat Jendral Bina Marga. 1992. Standar Perencanaan Geometri Untuk Jalan Perkotaan. Jakarta : Departemen Pekerjaan Umum.

Direktorat Jendral Bina Marga. 1997. Tata Cara Geometrik Jalan Antar Kota. Jakarta : Departemen Pekerjaan Umum.

Direktorat Jendral Bina Marga. 1997. Manual Kapasitas Jalan Indonesia. Jakarta : Departemen Perkerjaan Umum.

Direktorat Jendral Bina Marga. 2002. Pedoman Perencanaan Tebal Perkerasan Lentur. Jakarta : Departemen Pekerjaan Umum.

Departemen Permukiman Dan Prasarana Wilayah. 2004. Pedoman Konstruksi Dan Bangunan. Jakarta : Departemen Pekerjaan Umum.

Hobbs, F. D. 1995. Perencanaan Teknik Lalu Lintas. Yogyakarta : Gadjah Mada University Press.

Kholiq, Abdul. 2014. "Perencanaan Tebal Perkerasan Lentur Jalan Raya Antara Bina Marga Dan AASHTO 1993 (Studi Kasus : Jalan Lingkar Utara Panyingkiran Balibis Majalengka)". J-ENSITEC, Volume 1 Nomer 1 2014, halaman 43 51.

Morlok, Edward K. 1985. Pengantar Teknik Dan Perencanaan Transportasi. Jakarta : Erlangga.

Oglesby, Clarkson H. 1999. Teknik Jalan Raya Jilid 1. Jakarta : Gramedia.

Pradani, Novita, Muhammad Sadli, Dan Dewy Fithriayuni. 2016. "Analisis Perancangan Tebal Perkerasan Lentur Menggunakan Metode Bina Marga 2002, Metode Manual Desain Pekerjaan (MDP) Dan Metode Nottingham Pada Ruas Jalan I Gusti Ngurah Rai Palu”. Fropil. Volume 4 Nomer 2 2016, halaman 140 - 155.

Sukirman, Silvia. 1994. Dasar - Dasar Perencanaan Geometrik Jalan. Bandung : Nova.

-----------, Silvia. 2003. Beton Aspal Campuran Panas. Jakarta : Granit.

-----------, Silvia. 2007. Beton Aspal Campuran Panas. Jakarta : Yayasan Obor Indonesia.

Undang - Undang Republik Indonesia Nomer 38 Tahun 2004.

Undang - Undang Republik Indonesia Nomer 22 Tahun 2009. 
Wibowo, Joko. 2017. “Analisis Desain Perkerasan Jalan Metode Bina Marga 1987, Bina Marga 2002 Dan Evaluasi Struktur Perkerasan Jalan (Ruas Pelebaran Jalan Bantal - Mokomoko Bengkulu)". Skripsi. Surakarta : Universitas Muhamadiyah Surakarta. 